\title{
Nem um nem outro: Gottlob Frege, ambos
}

Victor Bernardo Chabu I

$\mathrm{E}$ M UM MUNDO que exige dos cientistas muitos artigos e muitas citações, esquecendo-se de pedir-lhes alguma ciência, Gottlob Frege seria ainda mais ignorado do que o foi em sua época. Matemático e professor em Jena, jamais alcançou o patamar máximo dessa carreira: mesmo uma promoção usualmente dada aos docentes sexagenários foi-lhe negada, com a justificativa de que seu percurso científico e sua obra seriam em demasiado inexpressivos para tal. Entretanto, por volta de um século após sua morte - e ao contrário da maioria dos outros doutores de Jena, devidamente condecorados aos sessenta anos -, Frege mereceu, ademais de uma página na Wikipédia disponível em umas cinquenta línguas, um extenso resumo biográfico na introdução do livro Lógica e Filosofia da Linguagem, que é, justamente, dedicado a apresentar ao público de língua portuguesa, em esmerada tradução direta dos originais, o importantíssimo trabalho que esse pesquisador, considerado de baixa produtividade, produziu.

...torna-se irrelevante o fato de inexistirem novas verdades em meu trabalho. Ficaria consolado com a convicção de que um desenvolvimento do método também faz progredir a ciência. Bacon pensava ser melhor inventar um meio pelo qual se pudesse descobrir facilmente algo a descobrir algo de particular...

Bem organizado por Paulo Alcoforado, doutor em Filosofia pela UFRJ (e conhecedor da Matemática), o livro traz, além da introdução esclarecedora sobre as principais questões abordadas pelo acadêmico alemão e seus desenvolvimentos teóricos daí suscitados, uma coletânea de textos de autoria do próprio Frege. Em ordem cronológica, podem-se ler excertos de publicações de sua juventude a sua maturidade, abordando tópicos tanto eminentemente matemáticos, como a formalização de uma teoria de números e o estabelecimento de uma linguagem matemática perfeita, auxiliada por uma notação adequada, quanto pronunciadamente filosóficos, basilares para a inauguração da lógica moderna, além de possuírem profundas implicações para o entendimento do fenômeno das linguagens humanas, pavimentando o caminho para o surgimento da semiótica.

...os sinais têm para o pensamento a mesma importância que para a navegação teve a descoberta de como usar o vento para navegar contra o vento...

Assim, ao lado de críticas a definições insuficientes para o conceito de função (aliás frequentes até hoje em livros didáticos, como a famosa função é uma regra que associa dois números...), suas reflexões sobre referência, sentido e ideia (noções nitidamente distintas no vocabulário fregeano) fornecem valiosas observações sobre o discurso verbal - o político, o quotidiano, o parafrástico, mesmo diretrizes para a tradução de um texto! Não é à toa que foi precisamente na interface desses dois campos que Frege assentou uma de suas maiores fundações, o Cálculo Proposicional, substituindo a estrutura lógica aristotélica, de 
sujeito e predicado (como em Sócrates é mortal), por uma nova, de função e argumento (a função ser mortal, calculada com o argumento Sócrates).

Agradando ao mesmo tempo públicos especializados em Exatas e em Filosofia, o que tornou-se inusitado na atualidade, Lógica e Filosofia da Linguagem vai além e satisfaz igualmente o leitor leigo, com a rara virtude de não privá-lo nem de acesso detalhado aos problemas enfrentados por Frege, nem de amplo entendimento - ainda que depois de uma leitura diligente - sobre como ele os encaminhou; há mesmo exemplos concretos de como Frege implementou parte das ideias matemáticas que discute, mas sem susto: os trechos mais árduos são tão difíceis (e tão instigantes!) quanto um sudoku. Curiosamente, porém, embora não seja técnico - e nem o poderia, pois tecnicamente Frege superou-se -, o livro é de especial interesse para os matemáticos.

...a tendência de criar nomes aos quais nenhum objeto corresponde é nefasta em um discurso com pretensão de rigor científico. Disso [conjunto universo] surgiram os paradoxos da teoria dos conjuntos, que a destruíram. Eu mesmo fui vítima dessa ilusão, ao querer conceber os números como conjuntos...

Os excertos apresentados são anteriores ao formalismo conjuntista que estrutura a Matemática, mas deixam antever alguns dos principais mecanismos da Teoria dos Conjuntos hodierna, como a concepção fregeana de cair um objeto sob um conceito (o que viria a ser a relação de pertinência), ou de cair um conceito em um outro (relação de continência), ou ainda os próprios objetos, um tanto parecidos com os atuais elementos de um conjunto. Frege adota duas instâncias teóricas atômicas, objeto e função, ao contrário da teoria contemporânea, que emprega apenas conjunto, capaz de englobar satisfatoriamente esses seus predecessores. Não por acaso, a despeito da riqueza de sua produção, ter confiado em uma teoria ingênua de conjuntos foi o que arruinou o programa principal de Frege. Ruína inescapável, como atesta o então incógnito Teorema da Incompletude, de Gödel, segundo o qual as operações aritméticas não podem proceder inteiramente de postulados lógicos.

...aponta-se a ambiguidade das expressões como uma fonte de erros lógicos. Considero igualmente oportuno precaver-se contra os nomes carentes de toda referência. O abuso demagógico apoia-se facilmente sobre isso: "a vontade do povo" pode servir de exemplo...

E eis aí outro motivo pelo qual o livro é fascinante. Paulo Alcoforado, podendo ainda melhorar a seleção de textos da coletânea, fê-lo com primor em sua segunda edição, recentemente publicada pela Edusp, permitindo-nos acompanhar de perto não apenas o homem genial, mas o pensador radicalmente honesto. Do tom visionário e jovem - que iria mudar o mundo - do prefácio de sua primeira publicação, passando pelos artigos acuados - mas não reticentes - em resposta às ferozes, todavia esparsas reações que suscitou, os textos insistentes clamando por atenção em meio à frieza com que seus trabalhos invariavelmente foram recebidos, até ao timbre maduro, consciente da profusão de inovações promovidas, apesar da falha em atingir o objetivo final; tudo isso depreende-se, passo a passo, das entrelinhas dos escritos selecionados para compor o livro. 
A presente edição mostra um Frege inconformista com mais vulto, vivendo um período em que a Matemática estava, para dizer o mínimo, bagunçada. Seus textos apontam com clareza os limites que a falta de uma axiomatização rigorosa impunham a ela e tentam, antes da pesquisa em matemática, a pesquisa para a Matemática: o desenvolvimento de um método que possibilitasse a essa ciência avanços consistentes e validasse seus resultados já obtidos, eliminando-lhes os paradoxos, as ambiguidades e as definições dúbias de que era pródiga. Um bocado como a Física Teórica de hoje. Certamente, os estudantes que se sentem pisando em ovos enquanto manipulam integrais de Feynman deveriam ler Lógica e Filosofia da Linguagem.

...os professores em vão se esforçam em explicar as funções, e são exatamente os alunos mais dotados aqueles que menos entendem, já que percebem que as definições dadas não se harmonizam com as explicações do professor...

Ora, pelo menos Frege ensina-nos, pela tradução de Alcoforado, que o medo maior de um grande cientista não é a falta de reconhecimento, porém descobrir-se uma fraude, e que não ser reconhecido mesmo tendo desenvolvido um trabalho de solidez e centralidade irrefragáveis não lhe é mais que uma decepção para com seus pares, nunca para consigo mesmo. Assim, compreende-se a sobriedade e a segurança com que escreve, já na última fase de sua vida e obra, revelando consciência quanto à importância de seus feitos e também um certo sabor mais incisivamente crítico em suas ponderações.

...a Matemática deveria ser um paradigma de clareza lógica. Na realida-

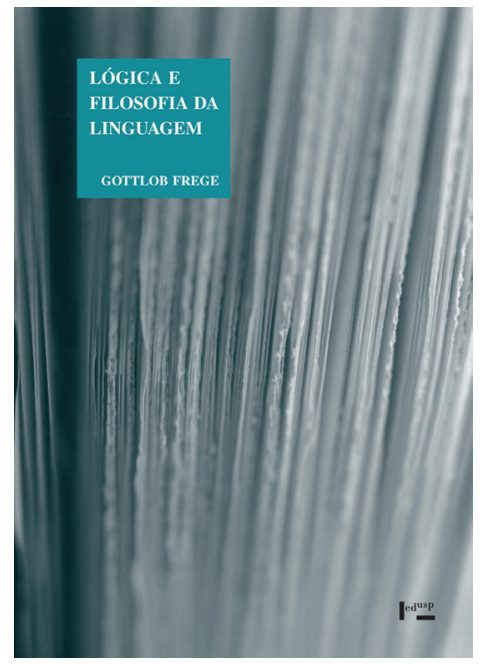

FREGE, G. Lógica e Filosofia da Linguagem. Trad. e org. Paulo Alcoforado. 2.ed. São Paulo: Edusp, 2009. 248p.

de, talvez não se achem nos textos de uma ciência tantas expressões errôneas, e consequentemente tantos pensamentos errôneos, como nos textos matemáticos. Nunca se deveria sacrificar a correção lógica à preocupação com concisão e brevidade...

Por tudo isso, a leitura de Lógica e Filosofia da Linguagem contribui, mais do que para a cultura, para a própria formação intelectual do leitor, seja ele leigo, seja filósofo ou matemático, transformando-o em uma desejável combinação dessas três condições. Afinal, como disse certa vez o próprio Gottlob Frege, “um filósofo que não tenha nenhuma familiaridade com a geometria é apenas um meio-filósofo, e um matemático que não tenha nenhuma veia filosófica é apenas um meio-matemático. Essas disciplinas afastaram-se uma da outra, em detrimento de ambas".

Já temos em mãos, todavia, uma óti- 
ma ferramenta para começarmos a deixar reaproximarem-se tais disciplinas e, por conseguinte, completarmo-nos intelectualmente. Aproveitemo-la!

Victor Bernardo Chabu é formado em Física pelo Instituto de Física da Universidade de São Paulo e pós-graduado em Física Matemática pelo King's College de Londres. @-victor.chabu@kcl.ac.uk

I King's College de Londres, Inglaterra. 